\title{
Interferon regulatory factor 5 genetic variants are associated with cardiovascular disease in patients with rheumatoid arthritis
}

Mercedes García-Bermúdez ${ }^{1 \dagger}$, Raquel López-Mejías ${ }^{2 \dagger}$, Fernanda Genre $^{2 \dagger}$, Santos Castañeda ${ }^{3}$, Javier Llorca ${ }^{4}$, Carlos González-Juanatey ${ }^{5}$, Alfonso Corrales², Begoña Ubilla², José A Miranda-Filloy ${ }^{6}$, Trinitario Pina², Carmen Gómez-Vaquero7, Luis Rodríguez-Rodríguez ${ }^{8}$, Benjamín Fernández-Gutiérrez ${ }^{8}$, Alejandro Balsa9 Dora Pascual-Salcedo ${ }^{9}$, Francisco J López-Longo ${ }^{10}$, Patricia Carreira ${ }^{11}$, Ricardo Blanco ${ }^{2}$, Javier Martín ${ }^{1}$ and Miguel A González-Gay ${ }^{2,12^{*}}$

\begin{abstract}
Introduction: Rheumatoid arthritis (RA) is a complex polygenic inflammatory disease associated with accelerated atherosclerosis and increased cardiovascular (CV) disease risk. Interferon regulatory factor 5 (IRF5) is a regulator of type I interferon induction. Recently, researchers have described an association between multiple single-nucleotide polymorphisms of the IRF5 gene and some rheumatic disorders. In this study, we aimed to evaluate whether three different haplotype blocks within the IRF5 locus which have been shown to alter the protein function are involved in the risk of $\mathrm{CV}$ events occurring in Spanish RA patients.

Methods: Three IRF5 polymorphisms (rs2004640, rs2070197 and rs10954213) representative of each haplotype group were genotyped by performing TaqMan assays using a 7900HT Fast Real-Time PCR System with tissue from a total of 2,137 Spanish patients diagnosed with RA. Among them, 390 (18.2\%) had experienced CV events. The relationship of IRF5 genotypes and haplotypes to CV events was tested using Cox regression.

Results: Male sex, age at RA diagnosis and most traditional risk factors (hypertension, dyslipidemia and smoking habit) were associated with increased risk for CV events in the RA population. Interestingly, a protective effect of both IRF5 rs2004640 GG and IRF5 rs10954213 GG genotypes against the risk for CV events after adjusting the results for sex, age at RA diagnosis and traditional CV disease risk factors was observed (hazard ratio $(H R)=0.6,95 \%$ confidence interval $(\mathrm{Cl})=0.38$ to $0.92, P=0.02$; and $\mathrm{HR}=0.58,95 \% \mathrm{Cl}=0.36$ to $0.95, P=0.03$, respectively). Moreover, we detected a protective effect of the GTG haplotype against the risk for CV events after adjusting the results for potential confounding factors ( $\mathrm{HR}=0.72,95 \% \mathrm{Cl}=0.56$ to $0.93, P=0.012$ ).
\end{abstract}

Conclusions: Our results reveal that IRF5 gene variants are associated with risk of CV events in patients with RA.

\footnotetext{
* Correspondence: miguelaggay@hotmail.com

${ }^{\dagger}$ Equal contributors

${ }^{2}$ Epidemiology, Genetics and Atherosclerosis Research Group on Systemic Inflammatory Diseases, Rheumatology Division, IDIVAL, Avenida Cardenal Herrera Oria s/n, 39011 Santander, Spain

${ }^{12}$ Cardiovascular Pathophysiology and Genomics Research Unit, School of Physiology, Faculty of Health Sciences, University of the Witwatersrand, 1 Jan Smuts Avenue Braamfontei, 2000 Johannesburg, South Africa

Full list of author information is available at the end of the article
} 


\section{Introduction}

Rheumatoid arthritis (RA) is a chronic inflammatory rheumatic disease associated with an increased risk for cardiovascular $(\mathrm{CV})$ events and $\mathrm{CV}$ disease-related deaths compared to the general population [1]. Because of that, adequate stratification of $\mathrm{CV}$ disease risk has special relevance in RA patients. Researchers in several studies have demonstrated that RA is an independent risk factor for premature heart disease [2]. This process is the result of a combined effect of traditional CV disease risk factors [3], the magnitude and severity of a chronic inflammatory response [4] and genetic factors located inside [4] and outside the human leukocyte antigen (HLA) region [5-8].

Type I interferons (IFNs) are signaling molecules involved in both innate and adaptive immunity. Misregulated expression of type I IFN genes has been observed in peripheral white blood cells of patients with several autoimmune diseases [9]. In this regard, interferon regulatory factor 5 (IRF5) has been involved in the regulation of type I IFN gene transcription $[10,11]$. This protein is critical for the production of proinflammatory cytokines [12], such as TNF- $\alpha$, interleukin 12 (IL-12) and IL-6, following Toll-like receptor signaling. IRF5 also acts as a molecular switch that controls inflammatory mechanisms mediated by macrophage cells [12].

IRF5 protein is encoded by the IRF5 gene, which is located in chromosome 7q32.1. Several genetic studies have described the relevance of multiple single-nucleotide polymorphisms (SNPs) of the IRF5 gene in different rheumatic disorders, such as RA and lupus erythematosus [13,14]. In this context, three groups of correlated IRF5 variants, designated as groups 1, 2 and 3, have been found to be independently associated with these inflammatory disorders and with different functional roles. Group 1 includes SNPs tagging a 30-bp in-frame insertion/deletion variant of exon 6 that alters protein stability. The association of group 2 SNPs seems to be explained by the T allele of IRF5 rs2004640 polymorphism that allows the expression of an alternative isoform and is associated with significantly higher levels of IRF5 expression. The association of group 3 SNPs is probably due to the rs10954213 A allele that creates an early polyadenylation site which leads to higher IRF5 expression [14].

Taking into account all of these considerations together in the present study, we analyzed the potential role of one tagging SNP of each group of independent signals (rs2004640, rs2070197 and rs10954213) in the risk for $\mathrm{CV}$ disease in a large and well-characterized cohort of patients with RA.

\section{Methods}

\section{Patients and study protocol}

A set of 2,137 Spanish patients with RA were included in the present study. Blood samples were obtained from patients recruited from University Hospital Lucus Augusti (Lugo), Marqués de Valdecilla University Hospital (Santander), Hospital de Bellvitge (Barcelona) Hospital Clínico San Carlos, La Paz University Hospital, Hospital de La Princesa, University Hospital Gregorio Marañón and 12 de Octubre University Hospital (Madrid). Informed written consent was obtained from all participants. The study was approved by the ethics committees of Galicia for University Hospital Lucus Augusti; of Cantabria for Marqués de Valdecilla University Hospital; of Cataluña for Hospital de Bellvitge; and of Madrid for Hospital Clínico San Carlos, La Paz University Hospital, Hospital de La Princesa, University Hospital Gregorio Marañón and 12 de Octubre University Hospital. All the patients fulfilled the RA classification criteria published by the American College of Rheumatology in 1987 and 2010 [15,16]. In all the cases, patients were assessed for the IRF5 rs2004640, rs2070197 and rs10954213 polymorphisms.

Data on the main demographic data, clinical characteristics, $\mathrm{CV}$ disease risk factors and $\mathrm{CV}$ events of patients enrolled in the study are shown in Table 1. Three hundred ninety (18.2\%) of the patients had experienced CV events. Definitions of $\mathrm{CV}$ events and traditional $\mathrm{CV}$

\section{Table 1 Demographic and clinical characteristics ${ }^{a}$}

\begin{tabular}{|c|c|}
\hline Clinical features & $\%(n / N)$ or mean \pm SD \\
\hline Patients & 2,137 \\
\hline \multicolumn{2}{|l|}{ Main characteristics } \\
\hline Age at disease onset (yr) & $53 \pm 14.8$ \\
\hline Follow-up duration (yr) & $12.5 \pm 8.25$ \\
\hline Females (\%) & 75.1 \\
\hline Rheumatoid factor-positive ${ }^{b}$ & $68.3(1,413 / 2,070)$ \\
\hline Anti-CCP antibody-positive & $57.3(1,024 / 1,785)$ \\
\hline Shared epitope-positive & $62.6(734 / 1,173)$ \\
\hline Erosions & $54.4(866 / 1,591)$ \\
\hline Extraarticular manifestations ${ }^{c}$ & $31.3(481 / 1,537)$ \\
\hline \multicolumn{2}{|l|}{ Cardiovascular risk factors } \\
\hline Hypertension & $40.3(846 / 2,100)$ \\
\hline Diabetes mellitus & $13.1(275 / 2,100)$ \\
\hline Dyslipidemia & $38.3(805 / 2,100)$ \\
\hline Obesity & $19.6(413 / 2,100)$ \\
\hline Smoking habit & $27.4(576 / 2,100)$ \\
\hline Patients with cardiovascular events (total) & $18.2(390 / 2,137)$ \\
\hline Ischemic heart disease & $8.5(181 / 2,137)$ \\
\hline Heart failure & $5.7(122 / 2,137)$ \\
\hline Cerebrovascular accident & $5.6(120 / 2,137)$ \\
\hline Peripheral arteriopathy & $2.8(60 / 2,137)$ \\
\hline \multicolumn{2}{|c|}{ 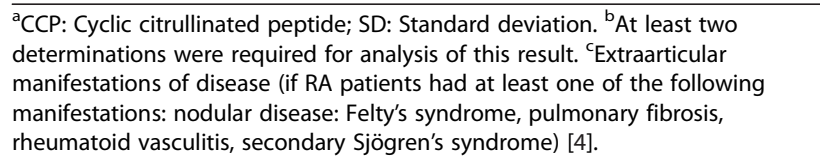 } \\
\hline
\end{tabular}


disease risk factors were established as previously described $[4,17]$.

\section{Genotyping}

Patient DNA was obtained from peripheral blood using standard methods. The IRF5 rs2004640, rs2070197 and rs10954213 polymorphisms were genotyped with predesigned TaqMan SNP genotyping assays in a 7900HT Fast Real-Time PCR System according to the conditions recommended by the manufacturer (Applied Biosystems, Foster City, CA, USA). Negative controls and duplicate samples were included to check the accuracy of genotyping.

\section{Statistical analysis}

The genotype data were checked for deviation from Hardy-Weinberg equilibrium (HWE) using a previously described method [18]. The relationship of genotypes, alleles and haplotypes to $\mathrm{CV}$ events that occurred in the follow-up was tested using Cox regression adjusted for sex, age at RA diagnosis and traditional $\mathrm{CV}$ disease risk factors. For that purpose, we used the most frequent genotype, allele and haplotype as reference variables. The end of follow-up was the first date of occurrence of the following: end of the study period, date of death or date of CV event. Follow-up time was estimated as the difference between the RA diagnosis date and the end of follow-up. Patients without $\mathrm{CV}$ events during the follow-up time and those who died by any non-CV-event-related cause were censored. The results are expressed as hazard ratios (HRs) with $95 \%$ confidence intervals (CIs). In order to have a reference population, 10,000 replications were generated by assigning $\mathrm{CV}$ events in randomized fashion to the actual studied population. The proportion of the risk for $\mathrm{CV}$ disease due to age at disease diagnosis, smoking history, hypertension and genetic variants at the IRF5 locus among the RA patients was estimated as the Nelson-Aalen cumulative HR. Comparative values between the different genetic models of inheritance for IRF5 polymorphisms were estimated using the Akaike Information Criterion (AIC). Statistical significance was defined as $P \leq 0.05$, and all analyses were performed using Stata SE/12 statistical software (Stata Corp, College Station, TX, USA).

\section{Results}

The IRF5 rs2004640, rs2070197 and rs10954213 polymorphism genotype distributions were in Hardy-Weinberg equilibrium. The genotyping success rate was greater than $98 \%$ in all cases. Genotype and allele frequencies of the IRF5 rs2004640, rs2070197 and rs10954213 polymorphisms were in agreement with the data in the HapMap database [19].

Table 2 describes those factors that were associated with the risk of $\mathrm{CV}$ disease in our cohort of RA patients. As expected, sex and most of the traditional CV disease risk factors (hypertension, dyslipidemia and smoking habit) were associated with increased risk of $\mathrm{CV}$ events $(P<0.05$ in all cases) (Table 2). Interestingly, when we analyzed the IRF5 rs2004640, rs2070197 and rs10954213 polymorphisms separately, we observed a protective effect of the IRF5 rs2004640 GG genotype against the risk

Table 2 Factors associated with cardiovascular events in a series of 2,137 rheumatoid patients $^{\mathrm{a}}$

\begin{tabular}{|c|c|c|c|c|}
\hline Variables & & HR $(95 \% \mathrm{Cl})$ & $P$-values & $P$-values ${ }^{b}$ \\
\hline Males (reference: females) & & $1.42(1.07$ to 1.87$)$ & 0.015 & \\
\hline Age at RA diagnosis (by each year) & & 1.07 (1.06 to 1.09$)$ & $<0.001$ & \\
\hline Hypertension & & 1.40 (1.029 to 1.92$)$ & 0.032 & \\
\hline Diabetes mellitus & & 1.18 (0.83 to 1.68$)$ & 0.344 & \\
\hline Obesity & & 0.93 (0.67 to 1.31$)$ & 0.702 & \\
\hline Dyslipidemia & & $1.42(1.05$ to 1.93$)$ & 0.022 & \\
\hline Smoking & & 1.58 (1.26 to 1.99$)$ & $<0.001$ & \\
\hline \multirow[t]{3}{*}{ rs $2004640^{c}$} & $\pi$ & 1 (reference) & - & - \\
\hline & TG & 1.07 (0.79 to 1.45$)$ & 0.664 & 0.670 \\
\hline & GG & 0.59 (0.38 to 0.92$)$ & 0.020 & 0.034 \\
\hline \multirow[t]{3}{*}{ rs $2070197^{c}$} & $\pi$ & 1 (reference) & - & - \\
\hline & $\mathrm{TC}$ & 1.16 (0.69 to 1.95$)$ & 0.58 & - \\
\hline & CC & 1.32 (0.32 to 5.52$)$ & 0.39 & - \\
\hline \multirow[t]{3}{*}{ rs10954213 } & $\mathrm{AA}$ & 1 (reference) & - & - \\
\hline & $A G$ & 0.95 (0.71 to 1.26$)$ & 0.73 & 0.738 \\
\hline & GG & $0.58(0.36$ to 0.95$)$ & 0.03 & 0.049 \\
\hline
\end{tabular}

${ }^{a} \mathrm{Cl}$ : Confidence interval; HR: Hazard ratio; RA: Rheumatoid arthritis. ${ }^{\mathrm{b}}$-values estimated on the basis of 10,000 replications. ${ }^{\mathrm{c}}$ Adjusted for sex, age at time of rheumatoid arthritis diagnosis and traditional cardiovascular disease risk factors (hypertension, diabetes mellitus, dyslipidemia, obesity, smoking habit). 
of $\mathrm{CV}$ events after adjusting the results for sex, age at RA diagnosis and traditional CV disease risk factors (hypertension, diabetes mellitus, dyslipidemia, obesity and smoking habit) $(\mathrm{HR}=0.6,95 \% \mathrm{CI}=0.38$ to $0.92, P=0.02$ ) (Table 2$)$. Additionally, the risk of CV disease was decreased in the group of RA patients who carried the IRF5 rs10954213 GG genotype after we adjusted the results for potential confounders $(\mathrm{HR}=0.58,95 \% \mathrm{CI}=0.36$ to $0.95, P=0.03$ ) (Table 2). These results were also significant after we estimated by simulation $(P=0.034$ and $P=0.049$ for the IRF5 rs2004640 GG and rs10954213 GG genotypes, respectively) (Table 2). However, we found no statistically significant differences when we assessed the IRF5 rs2070197 polymorphism according to the presence or absence of CV events (Table 2).

In a further step, we combined the three polymorphisms to create haplotypes (Table 3). As shown in Table 3, we detected a protective effect of the GTG haplotype after adjusting the results for sex, age at RA diagnosis and traditional $\mathrm{CV}$ disease risk factors $(\mathrm{HR}=$ $0.72,95 \% \mathrm{CI}=0.56$ to $0.93, P=0.012$ ).

Additional file 1: Table S1 describes the proportion of the $\mathrm{CV}$ disease risk disease for RA patients due to age at disease diagnosis, smoking history, hypertension and the genetic variants at the IRF5 locus. Additional file 2: Table $\mathrm{S} 2$ displays the genetic model of inheritance of our analysis. Interestingly, as shown in Additional file 1: Table S1, the presence of GG genotypes in the IRF5 rs2004640 and rs1095213 polymorphisms decreased CV disease risk in $0.7 \%$ and $1 \%$ of patients, respectively (Additional file 1 : Table S1). In addition, smoking, age at disease diagnosis and presence of hypertension increased the risk of $\mathrm{CV}$ disease (Additional file 1: Table S1). Further, as shown in Additional file 2: Table S2, the AIC estimation for the recessive model showed the lower level in the IRF5 rs2004640 and rs1095213 polymorphisms, which made it the preferable model for our study (Additional file 2: Table S2).

\section{Discussion}

$\mathrm{CV}$ disease is the most common cause of premature mortality in patients with RA [1,2]. The augmented CV

Table 3 Results of haplotype analysis in rheumatoid arthritis patients with vs. without cardiovascular disease ${ }^{a}$

\begin{tabular}{|c|c|c|c|c|}
\hline \multicolumn{3}{|c|}{ Haplotypes } & \multirow[t]{2}{*}{$\mathrm{HR}(95 \% \mathrm{Cl})^{\mathrm{b}}$} & \multirow[t]{2}{*}{ P-value } \\
\hline rs2004640 & rs2070197 & rs10954213 & & \\
\hline $\mathrm{T}$ & $T$ & A & 1 (reference) & - \\
\hline G & $\mathrm{T}$ & G & 0.72 (0.56 to 0.93 ) & 0.012 \\
\hline G & $\mathrm{T}$ & A & 0.85 (0.61 to 1.18$)$ & 0.34 \\
\hline T & C & A & 1.14 (0.75 to 1.74$)$ & 0.52 \\
\hline
\end{tabular}

${ }^{\mathrm{a}} \mathrm{Cl}$ : confidence interval; HR: hazard ratios. ${ }^{\mathrm{b}}$ Adjusted for sex, age at time of rheumatoid arthritis diagnosis and traditional cardiovascular disease risk factors (hypertension, diabetes mellitus, dyslipidemia, obesity and smoking habit). disease mortality observed in this pathology is the result of a compound effect mediated by traditional CV disease risk factors and chronic inflammation [3,4]. Because genes have also been associated with an increased risk of $\mathrm{CV}$ disease in RA, research in the past several years has been focused on the search for genetic markers that may improve the identification of RA patients at risk of experiencing CV events [4-8].

Outside the HLA region, IFN pathway genes, which encode cytokines with critical modulatory effects on innate and adaptive immunity, have been shown to represent a key component of the genetic network leading to autoimmune processes. In this context, several polymorphisms in the IRF5 gene (a regulator of type I IFN induction) $[10,11]$ are associated with an increased risk of immune-mediated diseases [13,14]. Because of that, in this study we analyzed three genetic variants (IRF5 rs2004640, rs2070197 and rs10954213) as representatives of three different IRF5 haplotype blocks [14]. To the best of our knowledge, our study constitutes the largest series of RA patients assessed for the potential influence of IRF5 polymorphisms in the risk of CV disease. Interestingly, when we studied each of the polymorphisms separately, our results revealed a protective effect of the IRF5 rs2004640 GG and IRF5 rs10954213 GG genotype variants against the risk of $\mathrm{CV}$ events in RA. Moreover, when we analyzed all the genetic variants together to create haplotypes, our results revealed a protective effect of the GTG haplotype (the one that carries both G alleles of IRF5 rs2004640 and rs10954213 polymorphisms) against the risk of $\mathrm{CV}$ disease. Because the protective effect of the mutant allele of the IRF5 rs2004640 and rs1095213 polymorphisms is seen only in homozygosis, we can conclude that our study is adjusted to a recessive model of inheritance. Additionally, the results derived from our study are in accordance with those obtained in other pathologies $[20,21]$. In this context, the results of a recent study of individuals diagnosed with RA revealed an association between the IRF5 rs2004640 polymorphism and subclinical atherosclerosis [22].

The results obtained in this study provide additional evidence on the potential role that genetic factors may play in the development of CV disease in RA. The search for genetic markers associated with $\mathrm{CV}$ disease in RA may be important to establishing a better characterization of RA patients at risk of CV disease. Improved understanding of these underlying genetic may be useful to establish future therapeutic targets to decrease the risk of $\mathrm{CV}$ disease in RA patients.

\section{Conclusion}

Our results reveal that IRF5 gene variants are associated with $\mathrm{CV}$ disease in RA patients. 


\section{Additional files}

Additional file 1: Table S1. Proportion of the CV risk for RA patients due to age, smoking history, hypertension and the genetic variants at the IRF5 locus at 5 years.

Additional file 2: Table S2. Comparison between different genetic models of inheritance for IRF5 polymorphisms.

\section{Abbreviations}

ACR: American College of Rheumatology; Anti-CCP: Anti-cyclic citrullinated protein/peptide antibody; Cl: Confidence interval; CV: Cardiovascular; HLA: Human leukocyte antigen; HR: Hazard ratio; IFN: Interferon; IL: Interleukin; IRF: Interferon regulatory factor; RA: Rheumatoid arthritis; SD: Standard deviation; SLE: Systemic lupus erythematosus; SNP: Single-nucleotide polymorphism; TNF: Tumor necrosis factor.

\section{Competing interests}

The authors declare that they have no competing interests.

\section{Authors' contributions}

MGB, RLM and FG carried out genotyping, participated in the study design and data analysis and helped to draft the manuscript. SC and BFG were involved in the acquisition and interpretation of data and in revising the manuscript critically for important intellectual content. $J$ carried out data analysis and interpretation. AC and CGJ performed the carotid ultrasound examination and were involved in the acquisition and interpretation of data as well as study coordination, and they helped to draft the manuscript. BU, JAMF, TP, CGV, LRR, AB, DPS FJLL, PC and RB participated in the acquisition and interpretation of data and helped to draft the manuscript. JM and MAGG made substantial contributions to the study's conception and design, data acquisition and study coordination, and they helped to draft the manuscript. All authors read and approved the final manuscript.

\section{Authors' information}

JM and MAGG share senior authorship of this article.

\section{Acknowledgements}

We wish to thank all the patients with RA who participated and made this study possible. We want to especially thank Sofía Vargas, Rodrigo Ochoa, M Luisa López, M Jesús Ibañez and Sara Olavarria for their technical assistance. This study was supported by European Union FEDER funds (European Fund for Regional Development) and the Health Research Fund (Fondo de Investigación Sanitaria grants PI06/0024, PS09/00748 and PI12/00060) from Instituto de Salud Carlos III (ISCIII, Health Ministry, Spain). It was also partially supported by Cooperative Health Research Thematic Network (RETICS) Program RD12/0009 (RIER) from Instituto de Salud Carlos III (ISCIII, Health Ministry, Spain) and by grants from the European Innovative Medicines Initiative Be the Cure (IMI BTCure) program. RLM is a recipient of a Sara Borrell postdoctoral fellowship from the Instituto Carlos III de Salud at the Spanish Ministry of Health (CD12/00425). FG and BU are supported by funds from the RETICS Program (RIER) (RD12/0009/0013).

\section{Author details}

${ }^{1}$ Institute of Parasitology and Biomedicine López-Neyra, IPBLN-CSIC, Parque Tecnológico de Ciencias de la Salud, Avenida del Conocimiento s/n, Armilla, 18100 Granada, Spain. Epidemiology, Genetics and Atherosclerosis Research Group on Systemic Inflammatory Diseases, Rheumatology Division, IDIVAL, Avenida Cardenal Herrera Oria s/n, 39011 Santander, Spain. ${ }^{3}$ Department of Rheumatology, Hospital Universitario la Princesa, IIS-Princesa, Diego de León 62, 28006 Madrid, Spain. ${ }^{4}$ Department of Epidemiology and Computational Biology, School of Medicine, University of Cantabria, and CIBER Epidemiología y Salud Pública (CIBERESP), IDIVAL, Avenida Cardenal Herrera Oria s/n, 39011 Santander, Spain. ${ }^{5}$ Cardiology Division, Hospital Universitario Lucus Augusti, Doctor Ochoa s/n, 27004 Lugo, Spain. ${ }^{6}$ Department of Rheumatology, Hospital Universitario Lucus Augusti, Doctor Ochoa s/n, 27004 Lugo, Spain. ${ }^{7}$ Department of Rheumatology, Hospital Universitario Bellvitge, Feixa Llarga s/n, 08907 Barcelona, Spain. ${ }^{8}$ Department of Rheumatology, Hospital Clínico San Carlos, Profesor Martín Lagos s/n, 28040 Madrid, Spain. ${ }^{9}$ Department of Rheumatology, Hospital Universitario La Paz, Paseo de la Castellana 261, 28046 Madrid, Spain. ${ }^{10}$ Department of
Rheumatology, Hospital General Universitario Gregorio Marañón, Doctor Esquerdo 46, 28007 Madrid, Spain. ${ }^{11}$ Department of Rheumatology, Hospital Universitario 12 de Octubre, Avenida de Córdoba s/n, 28041 Madrid, Spain. ${ }^{12}$ Cardiovascular Pathophysiology and Genomics Research Unit, School of Physiology, Faculty of Health Sciences, University of the Witwatersrand, 1 Jan Smuts Avenue Braamfontei, 2000 Johannesburg, South Africa.

Received: 11 March 2014 Accepted: 17 June 2014

Published: 10 July 2014

\section{References}

1. Avina-Zubieta JA, Thomas J, Sadatsafavi M, Lehman AJ, Lacaille D: Risk of incident cardiovascular events in patients with rheumatoid arthritis: a meta-analysis of observational studies. Ann Rheum Dis 2012, 71:1524-1529.

2. Solomon DH, Goodson NJ, Katz JN, Weinblatt ME, Avorn J, Setoguchi S, Canning C, Schneeweiss S: Patterns of cardiovascular risk in rheumatoid arthritis. Ann Rheum Dis 2006, 65:1608-1612.

3. Dessein PH, Norton GR, Woodiwiss AJ, Joffe BI, Wolfe F: Influence of nonclassical cardiovascular risk factors on the accuracy of predicting subclinical atherosclerosis in rheumatoid arthritis. J Rheumato/ 2007, 34:943-951.

4. Gonzalez-Gay MA, Gonzalez-Juanatey C, Lopez-Diaz MJ, Pineiro A, Garcia-Porrua C, Miranda-Filloy JA, Ollier WE, Martin J, Llorca J: HLA-DRB1 and persistent chronic inflammation contribute to cardiovascular events and cardiovascular mortality in patients with rheumatoid arthritis. Arthritis Rheum 2007, 57:125-132.

5. García-Bermúdez M, González-Juanatey C, López-Mejías R, Teruel M, Corrales A, Miranda-Filloy JA, Castañeda S, Balsa A, Fernández-Gutierrez B, González-Álvaro I, Gómez-Vaquero C, Blanco R, Llorca J, Martín J, González-Gay MA: Study of association of CD40-CD154 gene polymorphisms with disease susceptibility and cardiovascular risk in Spanish rheumatoid arthritis patients. PLOS One 2012, 7:e49214

6. García-Bermúdez M, López-Mejías R, Genre F, Castañeda S, GonzálezJuanatey C, Llorca J, Corrales A, Miranda-Filloy JA, Rueda-Gotor J, GómezVaquero C, Rodríguez-Rodríguez L, Fernández-Gutiérrez B, Pascual-Salcedo D, Balsa A, López-Longo FJ, Carreira P, Blanco R, González-Álvaro I, Martín J, González-Gay MA: SMAD3 rs17228212 gene polymorphism is associated with reduced risk to cerebrovascular accidents and subclinical atherosclerosis in anti-CCP negative Spanish rheumatoid arthritis patients. PLoS One 2013, 8:e77695.

7. López-Mejías R, García-Bermúdez M, González-Juanatey C, Castañeda S Miranda-Filloy JA, Gómez-Vaquero C, Fernández-Gutiérrez B, Balsa A, Pascual-Salcedo D, Blanco R, González-Álvaro I, Llorca J, Martín J, González-Gay MA: NFKB1-94ATTG ins/del polymorphism (rs28362491) is associated with cardiovascular disease in patients with rheumatoid arthritis. Atherosclerosis 2012, 224:426-429

8. López-Mejías R, Genre F, García-Bermúdez M, Corrales A, González-Juanatey C, Llorca J, Miranda-Filloy JA, Rueda-Gotor J, Blanco R, Castañeda S, Martín J, González-Gay MA: The ZC3HC1 rs11556924 polymorphism is associated with increased carotid intima-media thickness in patients with rheumatoid arthritis. Arthritis Res Ther 2013, 15:R152.

9. Higgs BW, Liu Z, White B, Zhu W, White WI, Morehouse C, Brohawn P, Kiener PA, Richman L, Fiorentino D, Greenberg SA, Jallal B, Yao Y: Patients with systemic lupus erythematosus, myositis, rheumatoid arthritis and scleroderma share activation of a common type I interferon pathway. Ann Rheum Dis 2011, 70:2029-2036.

10. Schoenemeyer A, Barnes BJ, Mancl ME, Latz E, Goutagny N, Pitha PM, Fitzgerald KA, Golenbock DT: The interferon regulatory factor, IRF5, is a central mediator of Toll-like receptor 7 signaling. J Biol Chem 2005, 280:17005-17012.

11. Barnes BJ, Moore PA, Pitha PM: Virus-specific activation of a novel interferon regulatory factor, IRF-5, results in the induction of distinct interferon a genes. J Biol Chem 2001, 276:23382-23390.

12. Krausgruber T, Blazek K, Smallie T, Alzabin S, Lockstone H, Sahgal N, Hussell T, Feldmann M, Udalova IA: IRF5 promotes inflammatory macrophage polarization and $\mathrm{T}_{\mathrm{H}} 1-\mathrm{T}_{\mathrm{H}} 17$ responses. Nat Immunol 2011, 12:231-238.

13. Eyre S, Bowes J, Diogo D, Lee A, Barton A, Martin P, Zhernakova A, Stahl E, Viatte S, McAllister K, Amos Cl, Padyukov L, Toes RE, Huizinga TW, Wijmenga C, Trynka G, Franke L, Westra HJ, Alfredsson L, Hu X, Sandor C, de Bakker PI, Davila S, Khor CC, Heng KK, Andrews R, Edkins S, Hunt SE, Langford C, Symmons D, et al: High-density genetic mapping identifies new susceptibility loci for rheumatoid arthritis. Nat Genet 2012, 44:1336-1340. 
14. Graham RR, Kozyrev SV, Baechler EC, Reddy MV, Plenge RM, Bauer JW, Ortmann WA, Koeuth T, González Escribano MF, Argentine and Spanish Collaborative Groups, Pons-Estel B, Petri M, Daly M, Gregersen PK, Martín J, Altshuler D, Behrens TW, Alarcón-Riquelme ME: A common haplotype of interferon regulatory factor 5 (IRF5) regulates splicing and expression and is associated with increased risk of systemic lupus erythematosus. Nat Genet 2006, 38:550-555.

15. Arnett FC, Edworthy SM, Bloch DA, McShane DJ, Fries JF, Cooper NS, Healey LA, Kaplan SR, Liang MH, Luthra HS, Medsger TA Jr, Mitchell DM, Neustadt DH, Pinals RS, Schaller JG, Sharp JT, Wilder RL, Hunder GG: The American Rheumatism Association 1987 revised criteria for the classification of rheumatoid arthritis. Arthritis Rheum 1988, 31:315-324.

16. Aletaha D, Neogi T, Silman AJ, Funovits J, Felson DT, Bingham CO 3rd, Birnbaum NS, Burmester GR, Bykerk VP, Cohen MD, Combe B, Costenbader KH, Dougados M, Emery P, Ferraccioli G, Hazes JM, Hobbs K, Huizinga TW, Kavanaugh A, Kay J, Kvien TK, Laing T, Mease P, Ménard HA, Moreland LW, Naden RL, Pincus T, Smolen JS, Stanislawska-Biernat E, Symmons D, et al: 2010 rheumatoid arthritis classification criteria: an American College of Rheumatology/European League Against Rheumatism collaborative initiative. Arthritis Rheum 2010, 62:2569-2581.

17. Gonzalez-Juanatey C, Llorca J, Martin J, Gonzalez-Gay MA: Carotid intima-media thickness predicts the development of cardiovascular events in patients with rheumatoid arthritis. Semin Arthritis Rheum 2009, 38:366-371.

18. Institut für Humangenetik: Case-Control Studies: Tests for Deviation from Hardy-Weinberg Equilibrium and Tests for Association. [http://ihg.gsf.de/ cgi-bin/hw/hwa1.pl]

19. International HapMap Project. [http://hapmap.ncbi.nlm.nih.gov/]

20. Carmona FD, Martin JE, Beretta L, Simeón CP, Carreira PE, Callejas JL, Fernández-Castro M, Sáez-Comet L, Beltrán E, Camps MT, Egurbide MV, the Spanish Scleroderma Group, Airó P, Scorza R, Lunardi C, Hunzelmann N, Riemekasten G, Witte T, Kreuter A, Distler JHW, Madhok R, Shiels P, van Laar JM, Fonseca C, Denton C, Herrick A, Worthington J, Schuerwegh AJ, Vonk MC, Voskuyl AE, et al: The systemic lupus erythematosus IRF5 risk haplotype is associated with systemic sclerosis. PLOS One 2013, 8:e54419.

21. Fan JH, Gao LB, Pan XM, Li C, Liang WB, Liu J, Li Y, Zhang L: Association between IRF-5 polymorphisms and risk of acute coronary syndrome. DNA Cell Biol 2010, 29:19-23.

22. Vosslamber S, van Sijl A, Bos CL, Lubbers J, de Ridder S, Voskuyl AE, Nurmohamed MT, Verweij CL: Interferon regulatory factor 5 (IRF5) gene variant rs2004640 is associated with carotid intima media thickness in rheumatoid arthritis patients [abstract A1.77]. Ann Rheum Dis 2014, 73:A34.

\section{doi:10.1186/ar4608}

Cite this article as: García-Bermúdez et al:: Interferon regulatory factor 5 genetic variants are associated with cardiovascular disease in patients with rheumatoid arthritis. Arthritis Research \& Therapy 2014 16:R146.

\section{Submit your next manuscript to BioMed Central and take full advantage of:}

- Convenient online submission

- Thorough peer review

- No space constraints or color figure charges

- Immediate publication on acceptance

- Inclusion in PubMed, CAS, Scopus and Google Scholar

- Research which is freely available for redistribution 